\title{
RELAÇÃO ENTRE CONSUMO ALIMENTAR E RENDA FAMILIAR NA CIDADE DE IGUAPE, S. PAULO (BRASIL)
}

\author{
Ignez Salas Martins* \\ Maria Lucia Ferrari Cavalcanti * \\ Rosa Nilda Mazzilli *
}

RSPU-B/336

MaRTINS, I. S. et al. Relação entre consumo alimentar e renda familiar na cidade de Iguape, S. Paulo (Brasil). Rev. Saúde públ., S. Paulo, 11: 27-38, 1977.

RESUmo: Estuda-se o consumo alimentar de uma amostra da populaçāo da localidade de Iguape, Estado de São Paulo, Brasil, relacionando-o com as variáveis renda e dieta equilibrada. Foi elaborada uma "Dieta Padrão", de custo minimo, que atendesse às recomendações nutricionais, aos hábitos alimentares e à disponibilidade local de alimentos. Para conhecer a possibilidade que teriam as familias estudadas de consumirem alimentaçāo equilibrada, foram estabelecidos cinco níveis de renda, segundo a proporção da renda familiar anual que necessitaria ser gasta para a aquisiçāo de uma dieta equivalente à "Dieta Padrão". A análise dos dados evidencia que o consumo médio per capita de calorias e proteinas da população estudada como um todo foi satisfatório, enquanto que o de vitamina $A$, tiamina, riboflavina, vitamina $C$ $e$ de cálcio foi insatisfatório. Quando se analisou o consumo de calorias, em relação aos cinco níveis de renda, o valor calórico total da dieta foi insatisfatório nos niveis mais baixos. Constatou-se inadequação de consumo calórico e protéico, respectivamente, em 10 a 20\% das famílias estudadas, cujas rendas seriam compativeis com aporte suficiente de calorias e proteinas.

UNITERmos: Alimentos, consumo. Renda familiar. Iguape, $\mathbb{S P}$, Brasil. Dieta padrão. Calorias, consumo. Proteinas, consumo.

\section{INTRODUC $\mathrm{A} O$}

O desenvolvimento global de grupos populacionais que anseiam por melhor qualidade de vida exige a participação ativa de cada um e de todos os seus integrantes. Essa participação conjunta no processo de desenvolvimento só será efetiva se a população desfrutar de altos níveis de saúde, compreendida no seu conceito positivo de bem estar físico, mental e social.
De há muito vem sendo comprovada a estreita relação entre nutrição e saúde, interferindo o estado nutricional na capacidade de aprendizagem, na produtividade física e mental, na personalidade, nas aspirações e na economia de um povo.

É evidente que o estado de nutrição e a saúde não podem ser melhorados nos países em desenvolvimento, sem que sejam propiciadas à população condições que

* Do Departamento de Nutrição da Faculdade de Saúde Pública da USP - Av. Dr. Arnaldo, 715 - São Paulo, SP - Brasil. 
MARTINS, I. $S$ et al. - Relacão entre consumo alimentar e renda familiar na cidade de Iguape, S Paulo (Brasil). Rev. Saúde públ., S. Paulo, 11:27-38, 1977.

permitam o consumo de uma alimentação equilibrada. Esta alimentação equilibrada. racional ou correta, é definida como a que fornece todos os nutrientes, em quantidades suficientes e harmônicas e é adequada para cada ser humano, tanto no que concerne às exigências fisiológicas das diferentes etapas do ciclo vital, quanto às suas peculiaridades sócio-psico-culturais.

Diante da definição apresentada e tendo em vista a manifestação de especialistas e de agências internacionais na área. da alimentação, nutrição e saúde, uma alimentação equilibrada continua a ser meta distante para a maioria da população mundial *.

Examinando-se tão somente os fatores determinantes do processo alimentação-nutrição ${ }^{11}$ - a) disponibilidade de alimentos (produção, comércio exterior, comercialização); b) aquisição de alimentos (capacidade econômica, educação em nutrição, orientação do consumidor); c) utilização dos alimentos (saneamento do meio, preparo adequado, distribuição intra-familiar, conservação doméstica dos alimentos); e d) aproveitamento biológico de nutrientes (fomento da saúde) - é forçoso reconhecer a imperiosa necessidade do estabelecimento de uma Política Nacional de Alimentação e Nutrição, inserida na política geral do desenvolvimento sócio-econômico de um país, a fim de que seja possível garantir a toda a população os alimentos $e$ as demais condições sócio-econômico-culturais indispensáveis para melhorar o seu estado nutricional e de saúde.

Para o planejamento de programas locais que visem a melhoria do estado nutricional da população, é importante analisar objetivamente o contexto sóciq-cultural e econômico da nutrição e identificar as variáveis que possam estar contribuindo para a situação alimentar existente na comunidade, entre elas, a renda familiar.

Embora estudos recentes em países desenvolvidos, revelem que a influência da renda sobre o consumo de nutrientes é bastante pequena ", nos países em desenvolvimento tal fato não ocorre. Provavelmente, nenhum outro fator isolado tem tanta influência sobre o estado nutricional de uma população como um todo. quanto a renda ${ }^{\text {? }}$

Sem dúvida, o dinheiro realmente afeta a dieta, afirmação que vem sendo comprovada pelo fato de que, por exemplo, nos países em desenvolvimento, as crianças mais desnutridas são geralmente provenientes de familias com rendas mais baixas ${ }^{1.2, ~} 2.13$.

Embora a renda familiar seja fator prioritário na aquisição de alimentos, levando qualquer aumento de ingresso à ingestão de maior quantidade de comida, cumpre ressaltar que alta renda nāo resulta necessariamente em difta equilibruda: observem-se, por exemplo, os atuais problemas de nutrição, prevalentes nos países industrializados (obesidade, doenças cardiovasculares, diabete), referidos na literatura como "doenças de excesso de consumo" ". Por outro lado, aumento da renda sem orientação em nutrição poderá levar a efeitos adversos ${ }^{10}$. E indiscutível que as "modas", "manias", falsas crenças e tabus alimentares existem em todos os países e grupos sócio-econômicos, influenciando negativamente o comportamento alimentar. Em todos os grupos populacionais há conhecimentos, atitudes e práticas errôneas de alimentação, suscetíveis de mudança. Tal fato reclama o desenvolvimento de programas de educação em nutrição e de orientação ao consumidor, além da exigência primeira de renda familiar suficiente para a aquisição de alimentos que propiciem dieta equilibrada.

Como o Departamento de Nutrição da Faculdade de Saúde Pública da Universidade de São Paulo realizou levantamentos do consumo alimentar em diversas localidades do Vale do Ribeira e, estando interessado em fornecer aos órgãos executivos, subsidios que pudessem de alguma forma contribuir para o planejamento 
MARTINS, I. S et al. - Relação entre consumo alimentar e renda familiar na cidade de Iguape, S. Paulo (Brasil). Rev. Saúde públ., S. Paulo, 11:27-38, 1977.

e implementação de programas de alimentação e nutrição nas cidades trabalhadas. decidimo-nos a examinar o consumo alimentar da localidade de Iguape, relarionando-o com as variáveis renda e dieta equilibrada. Assim propusemo-nos neste estudo a:

a) analisar a adequação do consumo de nutrientes em amostra da população;

b) estabelecer uma dieta equilibrada. que atendesse às recomendações nutricionais para a população amostrada. seus hábitos alimentares. disponihilidade local de alimentos e custo mínimo;

c) verificar. com base na dieta proposta. que possibilidades teriam as famílias estudadas de consumir alimentação equilibrada. partindo-se da pressuposição de que todos os alimentos que compöem a dieta tivessem de ser obtidos através da compra.

\section{METODOLOGIA}

\subsection{Descrição da área}

Iguape, município localizado no litoral sul do Estado de São Paulo. integra a sub-região do Vale do Ribeira, que tem sido alvo de estudos, enfocando os mais variados aspectos. tendo em vista subsídios para uma política de desenvolvimento da região.

A cidade de Iguape conheceu época florescente no Século XVIII. Enfrenta. entretanto, no momento. fase estacionária de desenvolvimento. condicionada principalmente pela dificuldade de acesso a outros centros urbanos.

$\mathrm{Na}$ época do presente estudo (1969). Iguape contava com uma população urbana de 7.269 habitantes. distribuídos em
1.375 famílias. dentre as quais $46.7 \%$ eram de funcionários públicos ou de assalariados. com renda mensal fixa; $21,7 \%$ de grandes e pequenos proprietários e $23.9 \%$ de famílias que viviam da renda diária obtida de pequenos serviços.

As fontes principais de renda da população são a atividade pesqueira e a agricultura. sendo o arroz, o feijão e a mandioca os produtos mais cultivados. A temporada de pesca abrange somente seis meses no ano, período de relativa fartura. no qual grande parcela da população consegue emprego. como diarista, na pesca ou em indústrias de conservas do peixe".

\subsection{Amostra}

O levantamento do consumo alimentar * foi realizado em amostra da população da cidade de Iguape, que abrangeu $337 \mathrm{fa}-$ mílias $(24.5 \%)$. por sorteio casual do total de famílias residentes na zona urbana do referido município paulista, considerando a família * como unidade amostral.

Os dados sobre a renda referem-se à sub-amostra das famílias que entraram no inquérito de consumo de alimentos, totalizando 194 famílias da amostra $(57,6 \%)$.

\subsection{Consumo Alimentar}

Para conhecer a ingestão alimentar foi utilizada a combinação do método de pesagem direta dos alimentos com o recordatório. obtendo-se, dessa forma, em duas risitas consecutivas, o consumo de alimentos durante as vinte e quatro horas de cada família, entrevistando-se diretamente a dona da casa ou a pessoa responsável pela alimentação no lar. 0 período de obtenção dos dados foi de sete dias. visando-se com isso reconhecer a variação

* Trabalho realizado como parte do programa do Departamento de Nutrição e do vale do Ribeira (atualmente SUDELPA), SP. 1969. Dados inédıtos.

* Família é definida como o grupo de pessoas, parentes entre si ou não, que comem al1. mentos preparados exclusivamente para o conjunto. 
MARTINS, I. S. et al. - Relaçāo entre consumo alimentar e renda familiar na cidade de Iguape, S Paulo (Brasil). Rev. Saúde piibl., S. Paulo, 11:27-38, 1977.

semanal do consumo de alimentos na comunidade investigada.

\subsection{Cálculo da "Dieta Padrão"}

Para atender a um dos objetivos do presente estudo. elaboramos uma dieta que atendesse às recomendaçōes nutricionais, segundo a composição familiar, os hábitos alimentares, a disponibilidade local dos alimentos e que fosse de custo mínimo. Convencionou-se chamar a esta dieta, "Dieta Padrão" (DP). Convém ressaltar que a DP refere-se à alimentação suficiente, completa, harmônica e adequada para a média dos indivíduos da comunidade de Iguape.

A quantidade dos diferentes nutrientes que a DP deveria fornecer foi baseada nas Recomendaçôes Nutricionais do $\mathrm{Na}$ tional Research Council (NRC). Academy of Sciences of Linited States, segundo a metodologia estabelecida pela FAO (Food and Agricultural Organization of United Nations) ${ }^{12}$.

Para o cálculo do conteúdo de nutrientes dos alimentos que compõem a DP (Tabela 1$)$ foi utilizada a Tabela de Composição Química dos Alimentos ${ }^{1.1}$.

$O$ custo mínimo da DP foi baseado no preço local dos alimentos. em vigor na época da realização, totalizando $\operatorname{Cr} \$ 468.00$ per capita anuais (1969).

\subsection{Renda Média Per Capita Anual por Família}

A renda média per capita anual foi calculada da seguinte maneira:

a) Para as famílias com salário mensal fixo, somou-se a ele a renda proveniente de outras fontes, como por exemplo: o valor locativo da residência, os alimentos colhidos das hortas domésticas, e outras.

b) Para as famílias de pescadores foram considerados dois períodos:

- o da pesca

- o da entressafra
A renda média semanal da temporada da pesca foi multiplicada pelo número de semanas que compõem esse período (26 semanas).

Para o periodo da entressafra, em que o mercado de trabalho diminui, fez-se a pressuposição de que o ganho daria exclusivamente para a compra de alimentos básicos e que, em média, as famílias consumiriam, por dia, as quantidades obtidas no dia do inquérito alimentar. Calculou-se. baseando-se no custo local dos alimentos, a renda de uma semana e multiplicou-se esse valor por 26. número de semanas da entressafra. ¿̀ soma da renda obtida nos períodos de safra e entressafra, juntou-se a estimativa do valor locativo da residência e obteve-se a renda total anual por família.

c) Para os não pescadores. calculou-se a renda média por semana e multiplicou-se esse valor por 52 (número de semanas do ano). Somou-se, a seguir, a estimativa do valor locativo da residência e da renda proveniente de outras fontes.

d) Para as famílias cuja renda era proveniente da venda e do consumo dos produtos da lavoura, calculou-se o valor dos alimentos consumidos pela família e somou-se a ele o ganho obtido através da venda da produção. Acrescentou-se ainda a estimativa do valor locativo da residência e da renda adquirida por outras fontes.

A renda média per capita anual por família foi obtida dividindo-se a renda total do ano pelo número de elementos da família. Para conhecer a possibilidade que teriam as famílias estudadas de consumir alimentação suficiente, completa, harmônica e adequada, tomou-se por hase o custo médio anual per capita da "Dieta Padrão" (Cr\$ 468.00*) e estabeleceram-se arbitrariamente, cinco clas-

Equivalente a US\$ 40.00 


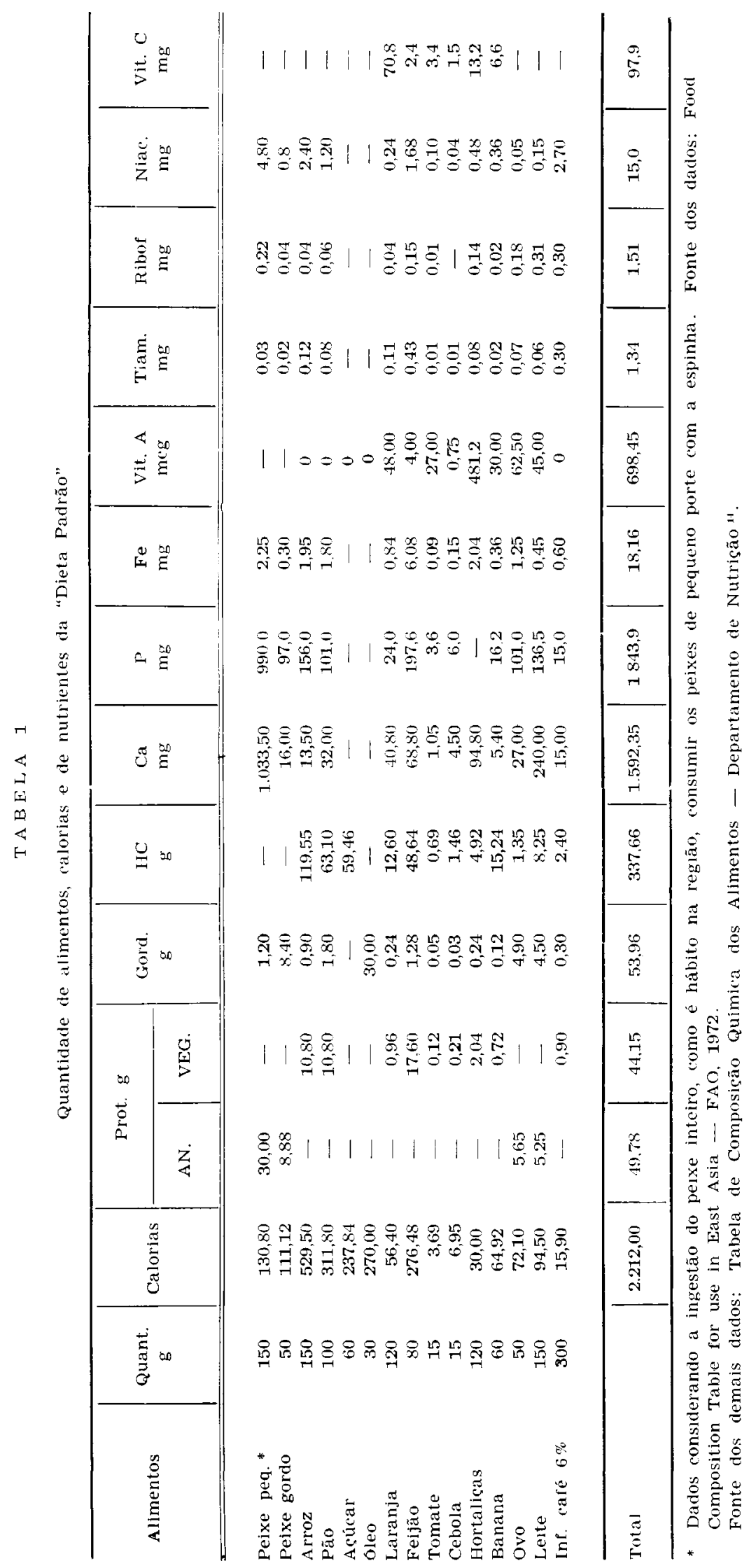


MARTINS, I. S. et al. - Relação entre consumo alimentar e renda familiar na cidade de Iguape, S. Paulo (Brasil). Rev. Saude públ., S. Paulo, 11:27-38, 1977.

\section{T A BELA 2}

Proporcão da renda familiar anual necessária para a aquisição da "Dieta Padrão (DP), ingresso per capita anual e niveis de renda, Iguape, Estado de São Paulo, 1969

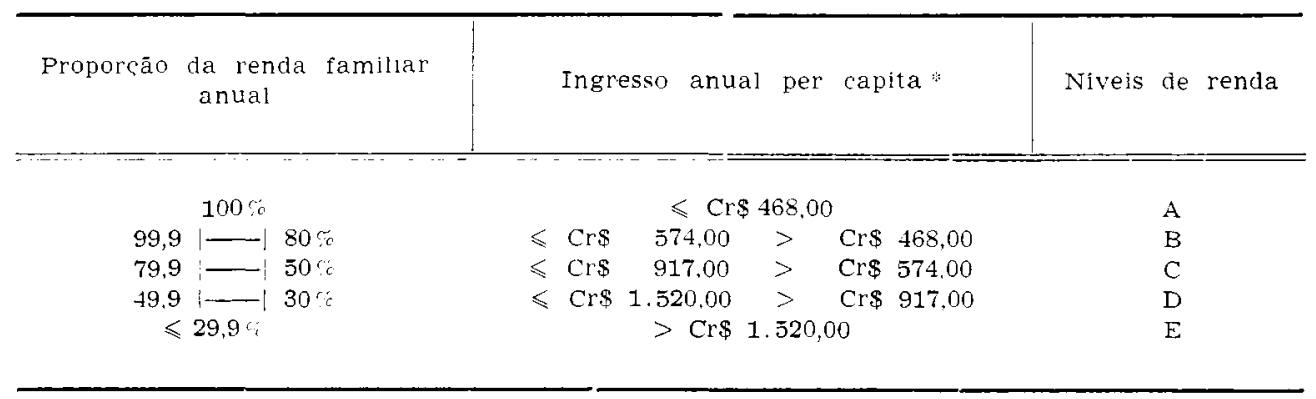

* Para equivalencla em dólar, dividir os totais por Cr\$ 11.00 (câmbio atual).

ses de famílias. baseadas na proporção da renda anual que precisaria ser gasta na aquisição de uma dieta equjvalente à DP. A partir desse critério. as famílias estudadas foram distribuídas em cinco níveis de renda (A. B, C. D. E). segundo o per capita anual da família (Tabela 21.

\section{RESLLTADOS E COMENTARIOS}

Analisando-se o consumo médio per capita diário de cada nutriente. constataram-se níveis satisfatórios para calorias, proteína. ferro, niacina e fósforo (Tabela 3). Entretanto. a adequação do consumo de cálcio e das vitaminas A e riboflavina foi acentuadamente baixa (Tabela 3). Convém ressaltar que a manjuba ou "enchora" (família Engraulidae), peixe mais consumido na localidade e que constitui importante fonte de vitamina $\mathrm{A}$ e de cálcio. é ingerida sem ser eviscerada e com a espinha, devido ao seu pequeno porte. Este fato. provavelmente concorra para a ingestão de vitamina A pré-formada e de cálcio. Considerando-se que a tabela da composição química dos alimentos, por nós utilizada para o cálculo do conteúdo de nutrientes. não leva em conla o teor do cálcio da espinha e o da vi-

\footnotetext{
* Equivalente LS\$ 40.00
}

tamina A das rísceras do peixe. é possivel que os valores encontrados para o consumo desses nutrientes na população estudada estejam subestimados.

O cálculo do consumo médio alimentar da população não traduz a real distribuição dos nutrientes entre as famílias. Por essa razão é importante analisar como se comporta a adequação do consumo de nutrientes entre as famílias (Tabela 4). Como se pode observar a ingestão média per capita de vitamina $C$, que teve percentagem de adequação satisfatória (Tahela 3), mostrou adequação de consumo ahaixo de $60 \%$ para cerca de $50 \%$ das famílias (Tabela 4). Com relação à riboflavina. também cerca de $50 \%$ das famílias se situaram nas faixas abaixo de $60 \%$ de adequação. As calorias e as proteínas foram consumidas em níveis acima de $100 \%$ de adequação por 55 e $77 \%$ das famílias, respectivamente. Como o inquérito alimentar foi realizado durante a temporada de pesca, época em que as famílias assalariadas recebem parte do salário em espécie, é provável que esse fato tenha contribuído para a melhoria do padrão alimentar, mesmo para aquelas famílias de níveis haixos de renda.

Tendo sido feita a distribuição da subamostra da população estudada em cinco niveis de renda. foi possivel analisar co- 
MARTINS, I. S. et al. - Relação entre consumo alimentar e renda familiar na cidade de Iguape, S. Paulo (Brasil). Rev. Saúde públ., S. Paulo, 11:27-38, 1977.

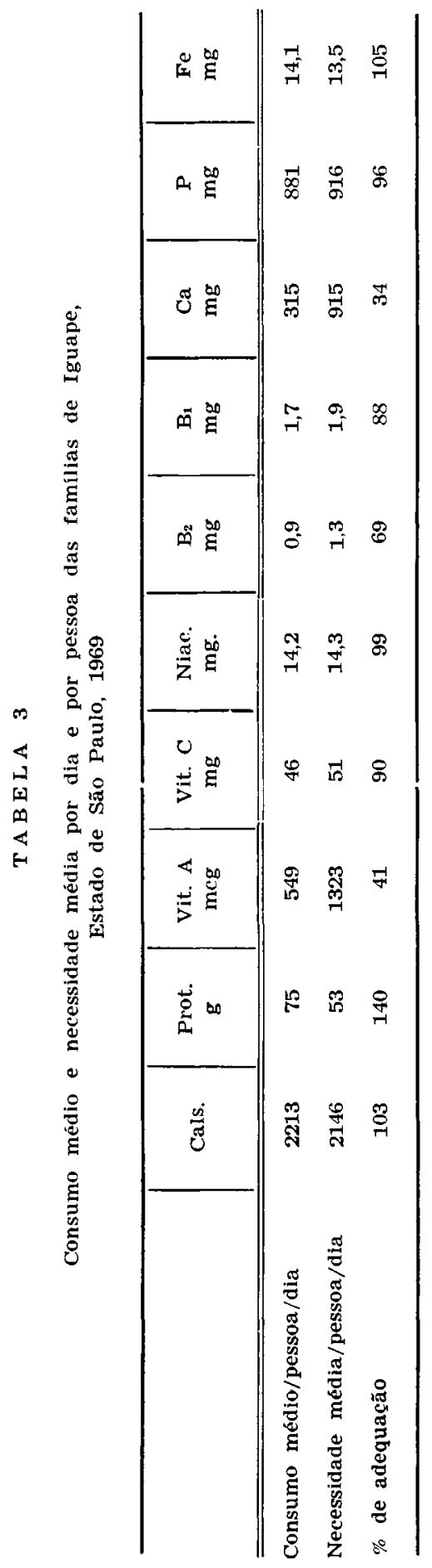


MARTINS, I. S. et al. - Relação entre consumo alimentar e renda familiar na cidade de Iguape, S. Paulo (Brasil). Rev. Saúde públ., S. Paulo, 11:27-38, 1977.

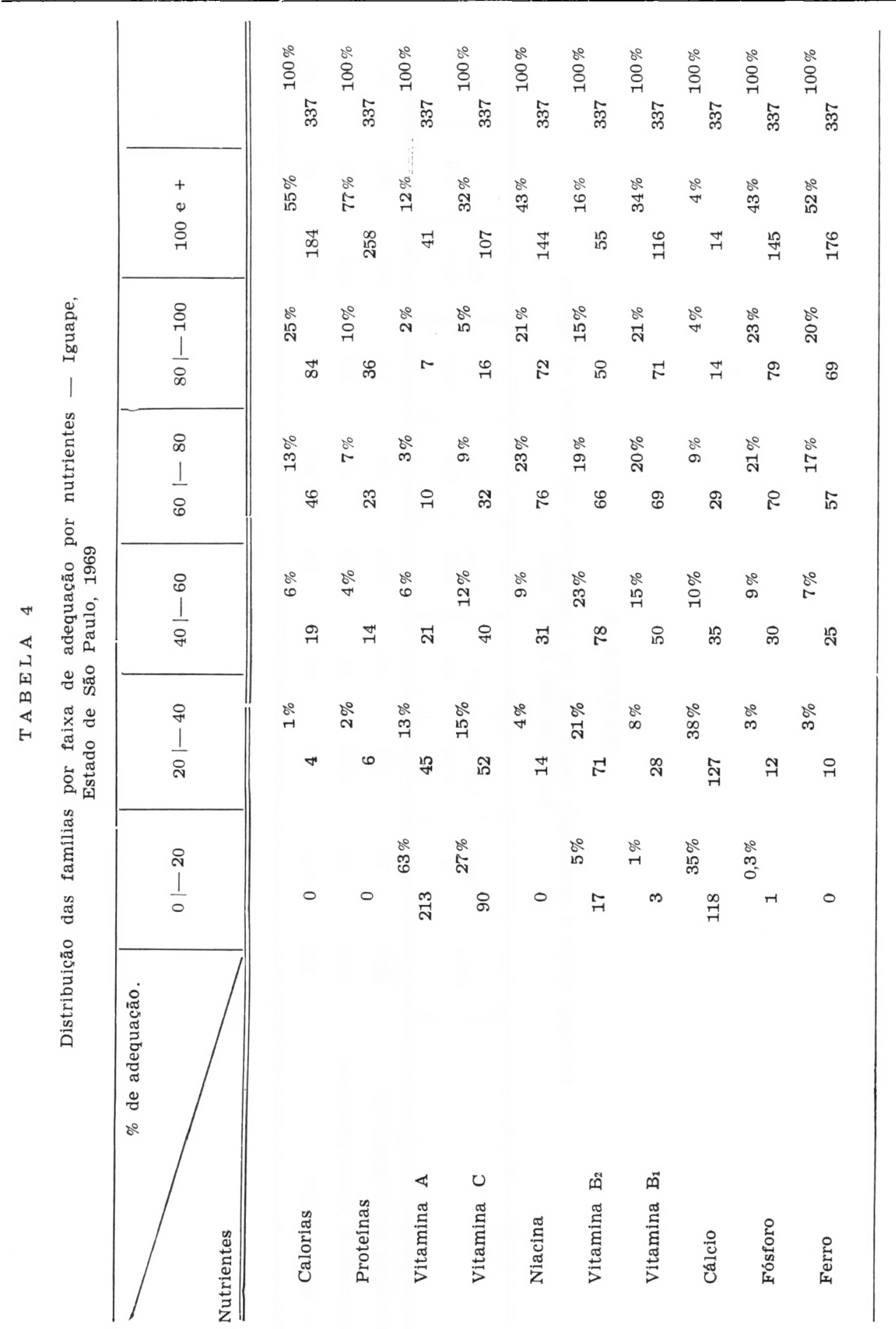


MARTINS, I. S. et al. - Relação entre consumo alimentar e renda familiar na cidade de Iguape, S. Paulo (Brasil). Rev. Saúde públ., S. Paulo, 11:27-38, 1977.

mo se comportou o consumo de calorias, proteínas e dos demais nutrientes, segundo esses níveis de renda (Figuras $1,2,3$ ). Pôde-se também constatar qual a proporção de famílias dentro de cada nível de renda (Tabela 5) e evidenciar a percentagem da renda familiar que deveria ser gasta para a aquisição de uma alimentação correspondente à "Dieta Padrão" se todos os produtos alimentícios tivessem que ser adquiridos através da compra, situação existente na entressafra (Tabela 5).

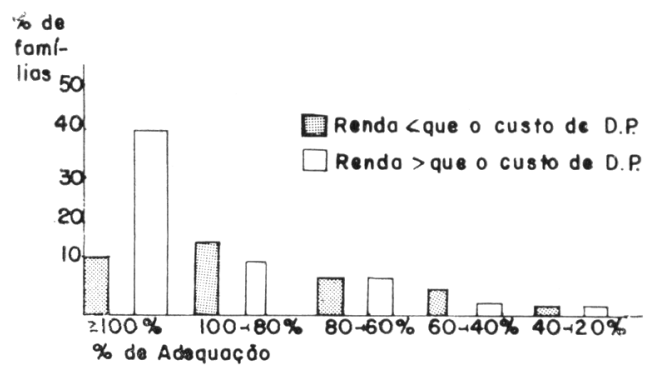

Fig. 1 - Adequação do consumo de calorias em familias com renda per capita média anual acima e abalxo do custo da DP.

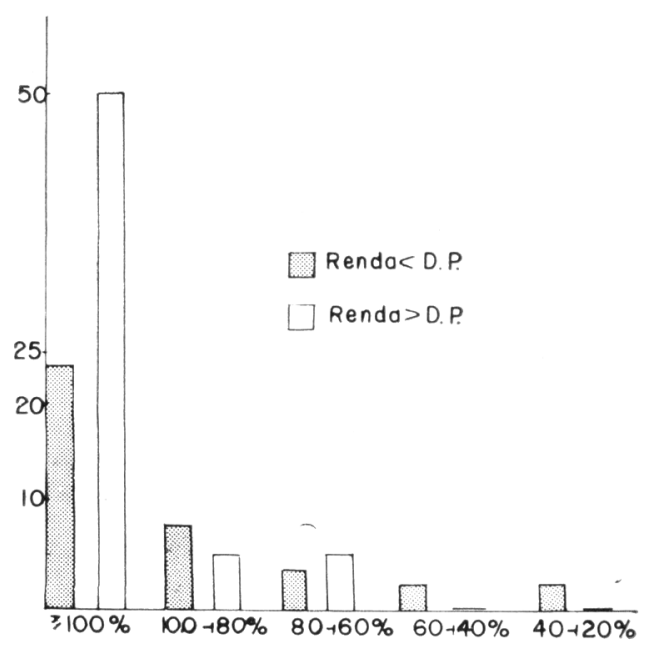

Fig. 2 - Adequação do consumo de proteinas em famílias com renda per capita média acima e abaixo do custo da DP.
A Figura 1 mostra que o consumo de calorias está relacionado com a renda. O consumo de proteínas mostrou comportamento semelhante (Figura 2); $50 \%$ das famílias com renda acima e $23 \%$ com renda abaixo do custo anual per capita da DP, apresentaram adequaçấo protéica acima de $100 \%$. Torna-se relevante, entretanto, observar que, aproximadamente 20 e $10 \%$ das famílias, respectivamente, com niveis suficientes de renda para a aquisição da DP, consumiram calorias e proteínas em faixas insatisfatórias de adequação. Possivelmente os alimentos em tais famílias não representam prioridade nos gastos da casa. Depreende-se daí que a educação em nutrição pode ser um instrumento importante na melhoria do padrão alimentar de uma população, mormente no caso de Iguape, em que todos residem em casa própria e não há necessidade de despesas com transportes para o trabalho.

Ao analisarmos a Figura 3, que apresenta o consumo médio de calorias e a contribuição dos nutrientes energéticos para o valor calórico total (VCT), segundo os cinco níveis de renda, em confronto com a DP, verificamos que nos niveis mais baixos de renda a participação das proteínas nas calorias totais da dieta é baixa, apesar de se tratar de zona pesqueira. O valor calórico total da dieta alcançou um consumo médio recomendável a partir do nível $\mathrm{C}$ (Figura 3 ).

Os hidratos de carbono parecem ser a fonte calórica mais acessivel na localidade, porquanto a sua participação no VCT da dieta variou entre 60 e $70 \%$.

Para se avaliar o comportamento do consumo de nutrientes em relação ao nível de renda, considerando-se não só as proteínas e calorias, mas também os demais princípios nutritivos necessários, foi aplicado o teste não paramétrico de Wilcoxon ${ }^{4}$. Atribuiu-se o valor -1 para cada nutriente cujo consumo foi abaixo 
MARTINS, I. S. et al. - Relação entre consumo alimentar e renda familiar na cidade de Iguape, S. Paulo (Brasil). Rev. Saúde públ., S. Paulo, 11:27-38, 1977.

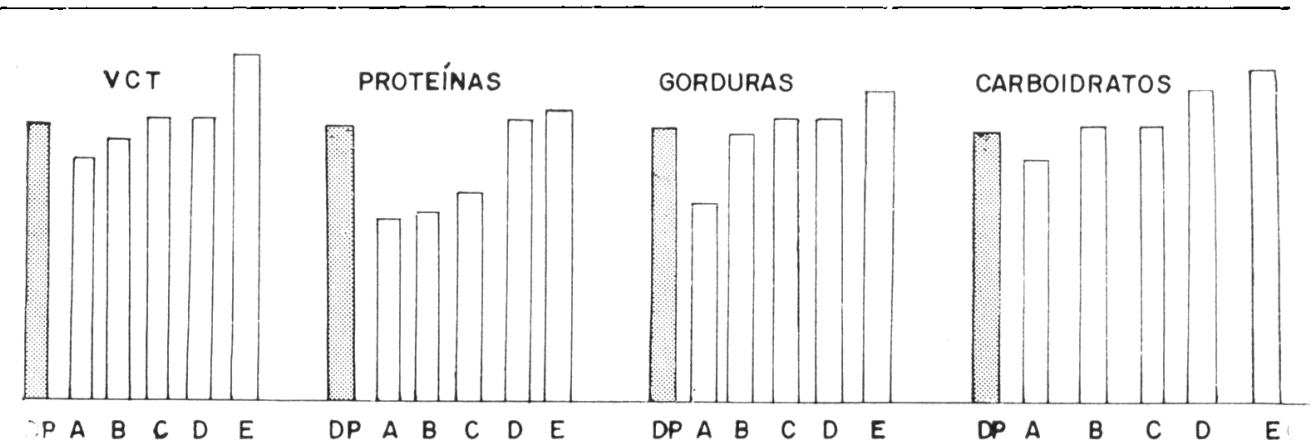

Fig. 3 - Consumo de proteínas, gorduras, carboidratos e valor calórico total da dieta em cinco níveis de renda e sua relação com a dieta padrão.

T A B E L A 5

Distribulção das familias segundo a proporção da renda familiar anual que necessitaria ser gasta para o consumo de uma dieta equivalente à Dieta Padrão - Iguape, Estado de São Paulo, 1969

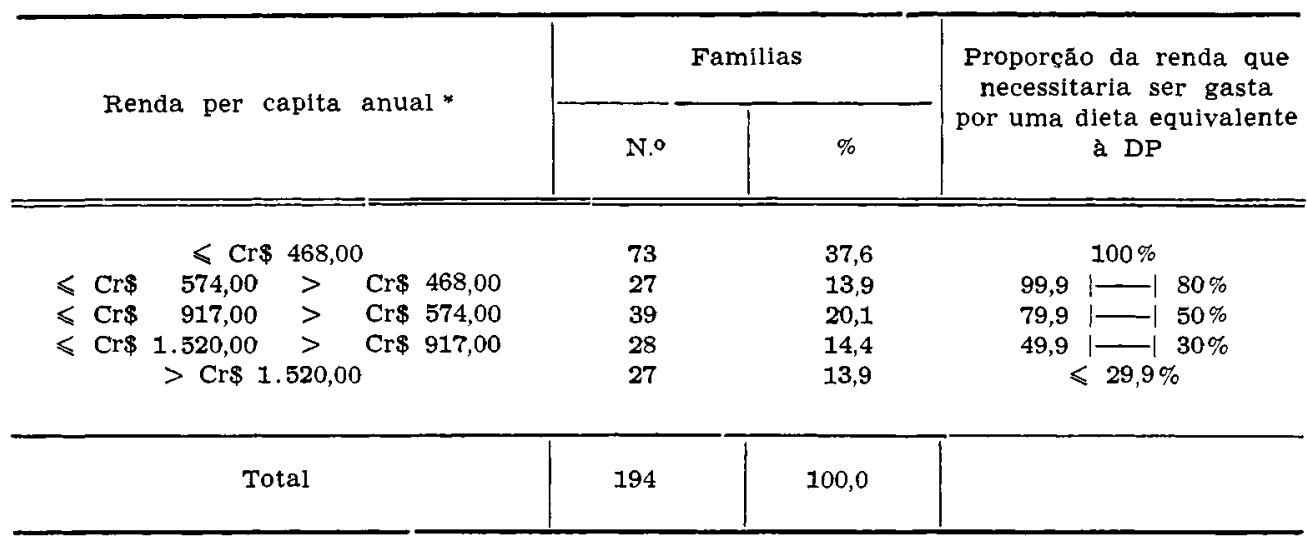

* Para equivalência em dólar, dividir os totais por $\mathrm{Cr} \$ 11,00$ (câmbio atual).

de $40 \%$ de adequação; o valor zero para os niveis de adequação entre 40 e $80 \%$; o valor +1 para os níveis acima de $80 \%$ de adequação. A soma obtida dos valores atribuídos aos nutrientes de cada família foi correlacionada com a renda anual per capita da respectiva família. A correlação foi significante para um limite de confiança de $90 \%$.

\section{CON C L U S O E S}

Os resultados obtidos permitiram-nos concluir que:
- o consumo médio per capita de calorias e de proteínas da população estudada foi satisfatório, enquanto que o de vitamina $A$, tiamina, riboflavina, vitamina $C$ e de cálcio foi insatisfatório;

-- na análise da distribuição do consumo de nutrientes entre as famílias constatou-se que a vitamina $\mathrm{A}$ e o cálcio tiveram uma adequação de consumo deficiente na maior parte das famílias;

- a utilização do teste não paramétrico de Wilcoxon evidenciou uma correlação positiva entre renda e consumo alimentar; 
MARTINS, I. S. et al. - Relação entre consumo alimentar e renda familiar na cidade de Iguape, S. Paulo (Brasil). Rev. Saúde públ., S. Paulo, 11:27-38, 1977.

- foi baixa a contribuição das proteínas para o VCT nos níveis mais baixos de renda; os hidratos de carbono foram a fonte calórica predominante;

- o VCT da dieta foi insatisfatório nos niveis mais baixos de renda;
- se constatou inadequação de consumo protéico e calórico em 10 e $20 \%$, respectivamente, das famílias estudadas, cuja renda seria compatível com um aporte suficiente de proteinas e calorias.

RSPU-B/336

MaRTINS, I. S. et al. [Food consumption related to income in Iguape, State of S. Paulo (Brazil).] Rev. Saúde públ., S. Paulo, 11:27-38, 1977.

ABSTRACTS: The present paper is a study of food consumption related to income and balanced diet as variables in a sample of the population of Iguape, State of São Paulo, Brazil. A theoretical "Standard Diet" was established respecting nutritional recommendations, feeding habits and local food availability. In order to know the possibility the families under study, would have of buying food which would make up the "Standard Diet" five levels of income were established based on the proportion of the annual family income that should be alloted to expenditure with food. The data revealed that the overall average "per capita" consumption was satisfactory regarding calories and proteins but unsatisfactory regardind vitamin $A$, thiamine, riboflavine, vitamin $C$ and calcium. However, analyses of data, when related to the income levels showed that calorie intake was unsatisfactory in the lower ones. Considering families whose income permitted an adequate calorie intake, 10 per cent had an inadequate calorie intake and 20 per cent inadequate protein intake.

UNITERMS: Food consumption, S. Paulo, Brazil. Family income. Diet. Calorie consumption. Protein consumption.

\section{REFERENCIAS BIBLIOGRAFICAS}

1. BATISTA FILHO, M. - Prevalência $e$ estágios da desnutrição protéico ca. lórica em crianças da cidade de São Paulo. São Paulo, 1976 [Tese de Doutoramento - Faculdade de Saúde Pública da USP].

2. BERG, A. - Nutrição e desenvolvimento econômico. Diálogo, $7(3): 55-62$, 1974.

3. DAVIDSON, S, et al. - Human nutrition and dietetics. $5^{\text {th }}$ ed. London Churchill Livingstone, 1972.

4. GINDLER, E.M. - Some nonparametric statistical for quick evaluation of clinical data. Clin. Chem., 21:309$14,1975$.

5. JACOBY, A. et al. - Influence of some social and environmental factors on the nutriente intake and nutritional status of school-children. Brit. J. prev. soc. Med., 29:116-20, 1975.

6. LESER, W.P. - Crescimento e nivel de saúde na cidade de São Paulo. Probl. bras., 12:16-30, 1974.

7. LEVINSON, F.J. - Morinda: an eco. nomic analysis of malnutrition among young children in rural India. Cambridge, Mass., Cornell-MIT, 1974. (Cornell/MIT International Nutrition Policy Series).

8. LORSTAD, M.H. - Estimación de la incidencia de la desnutrición. Notic. Nutr., 12:1-12, 1974.

9. MARTINS, I.S. - Estudo da situação sócio-economica do consumo de nu- 
MARTINS, I. S. et al. - Relação entre consumo alimentar e renda familiar na cidade de Iguape, S. Paulo (Brasil). Rev. Saúde públ., S. Paulo, 11:27-38, 1977.

trientes em comunidades do Vale do Ribeira. São Paulo, 1970. [Dissertação de mestrado - Faculdade de Saúde Pública da USP].

10. PÉRISSE, J.; SIZARET, F. \& FRANCOIS, P. - Efectos de los ingresos sobre la estructura de la ración ali. mentaria. Notic, Nutr., 7:1-10, 1969.

11. RECALDE, F. - Marco conceptual para el estabelecimiento de politicas nacionales de alimentación y nutrición en America Latina. Notic. Nutr., 9:17-27, 1971.

12. REH, E. - Manual para las encuestas alimentarias. Roma - FAO, 1972. (FAO - estudios sobre nutrición, 18).
13. SIGULEM, D.M. et al. - Aspectos epidemiológicos de verminoses, anemia e desnutrição protéico-calórica em pré.escolares do município de são Paulo. [Trabalho apresentado no IV Congresso Brasileiro de Nutrição, Rio de Janeiro, 1974].

14. UNIVERSIDADE DE SÃO PAULO, Faculdade de Saúde Públíca, Departamento de Nutrição. Tabela de composição quimica dos alimentos: compilaça de varias tabelas nacionais $e$ estrangeiras. São Paulo, 1971. [Mimeografado].

Recebido para publicação em 04/08/1976 Aprovado para publicação em 10/09/1976 